\title{
Wetting properties of aqueous short-chain alcohols' solutions
}

\author{
Andrzej Mizerski ${ }^{1, *}$ \\ ${ }^{1}$ The Main School of Fire Service, Faculty of Fire Safety Engineering, 52/54 Slowackiego St., 01-629 \\ Warsaw, Poland
}

\begin{abstract}
The article presents results of research on the wetting ability of aqueous solutions of short-chain alcohols in relation to selected hydrophobic materials. Polyethylene and Teflon were used as standard hydrophobic smooth materials. Dried peat with granulation $\mathrm{d}<0.5 \mathrm{~mm}$ was used as the porous hydrophobic material. Physical properties of alcohols and their solutions having a direct influence on the rate of saturation of capillary layers have been discussed. The wettability of smooth surfaces was characterized by the advancing and receding contact angles and wetting tension, defined as the product of the liquid surface tension and cosine of contact angle. The contact angles were determined by Wilhelmy's method using the Krüss K-100 tensiometer. Wettability of peat was determined by measuring the mass rate of liquid imbibition by capillary forces. For comparison, analogous tests of wettability and capillary imbibition rates were carried out using sodium dodecyl sulfate solutions and solutions of typical wetting agent used in firefighting activities. The solutions of surfactants, in the range of concentrations used in extinguishing operations, showed much better wetting properties in relation to a smooth hydrophobic surface (polyethylene) than solutions of alcohols in the entire range of concentrations (up to 100\%). The imbibition capacity of the hydrophobic peat layers of alcohol solutions with concentrations above $10 \%$ was higher than the solutions of surfactants.
\end{abstract}

\section{Introduction}

Short-chain aliphatic alcohols: ethanol, 1-propanol and 2-propanol, are widely used in the chemical, household chemicals, food (ethanol) and cosmetic industries, as both reagents and solvents for many water-insoluble substances. They have very good wetting properties, and ethanol is frequently used as the wettability standard in comparative tests, in particular in the testing of wettability of bulk materials. These alcohols mix well with water. It can therefore be assumed that aqueous solutions of alcohols could be used for wetting of hydrophobic bulk materials and structural porosities, i.e. where the use of surfactant solutions is ineffective.

Physical properties of aqueous solutions of short-chain alcohols, such as density, viscosity, surface tension, contact angles, refractive index, were investigated and quoted by

\footnotetext{
*Corresponding autor: amizerski@sgsp.edu.pl
} 
many authors [1-6]. They include the parameters found in the Washburn equation that describes the flow of liquid through a bundle of cylindrical capillaries, which can also describes the imbibition of liquids into porous materials:

$$
l^{2}=\frac{r \cdot \sigma \cdot \cos \theta \cdot \tau}{2 \eta}
$$

where: 1 - the length of the wetted section of the capillary, $r$ - the radius of the capillary (pore), $\sigma$ - the surface tension of the liquid, $\theta$ - the wetting angle of the material with liquid, $\tau$ - time of wetting, $\eta$ - liquid viscosity. The product $\sigma \cdot \cos \theta$ is called the wetting tension.

Short-chain alcohols mix with water in all ratios, but do not form ideal solutions. They form azeotropic mixtures and exhibit volume effects (volume decrease in alcohol-water mixtures). The physical parameters of the solutions are not additive quantities. A characteristic example is surface tension. The shape of the surface tension isotherms indicates the occurrence of surface excess concentration. Fig. 1 shows the isotherms of the surface tension of alcohols, made on the basis of literature data [1] and for comparison the isotherm of the surface tension of a wetting agent used in extinguishing operations.

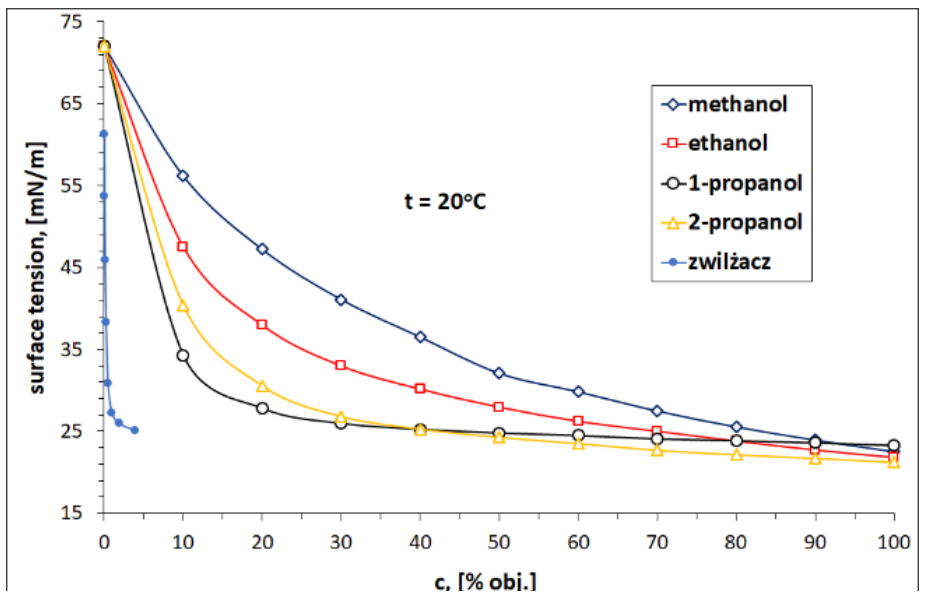

Fig. 1. Surface tension isotherms of short-chain alcohols. Based of [1].

The solutions of alcohols in water are not micellar solutions, however the shape of the isotherms indicates the presence of some kind of aggregates of alcohol molecules. They begin to form at concentrations that can be determined in the same way as critical micelle concentrations of surfactants. The determined concentration values, which can be called aggregation concentrations, are: methanol $-6 \mathrm{~mol} / \mathrm{dm}^{3}$ (24\% vol.), ethanol $-2.8 \mathrm{~mol} / \mathrm{dm}^{3}$ (16.1\% vol.), 1-propanol - $1.5 \mathrm{~mol} / \mathrm{dm}^{3}$ (11.3\% vol.), 2-propanol - $1.8 \mathrm{~mol} / \mathrm{dm}^{3}(13.5 \%$ vol.).

The viscosities of pure alcohols are higher than the viscosity of water $(1.0 \mathrm{mPa} \cdot \mathrm{s}$ at $20^{\circ} \mathrm{C}$ ). The dynamic viscosity of ethanol is $1.2 \mathrm{mPa} \cdot \mathrm{s}, 1$-propanol $-2.3 \mathrm{mPa} \cdot \mathrm{s}$, and 2propanol $-2.2 \mathrm{mPa} \cdot \mathrm{s}$ at $20{ }^{\circ} \mathrm{C}$. The viscosity of the alcohol solutions does not change linearly with the concentration, but shows a maximum (Fig. 2) [3]. 


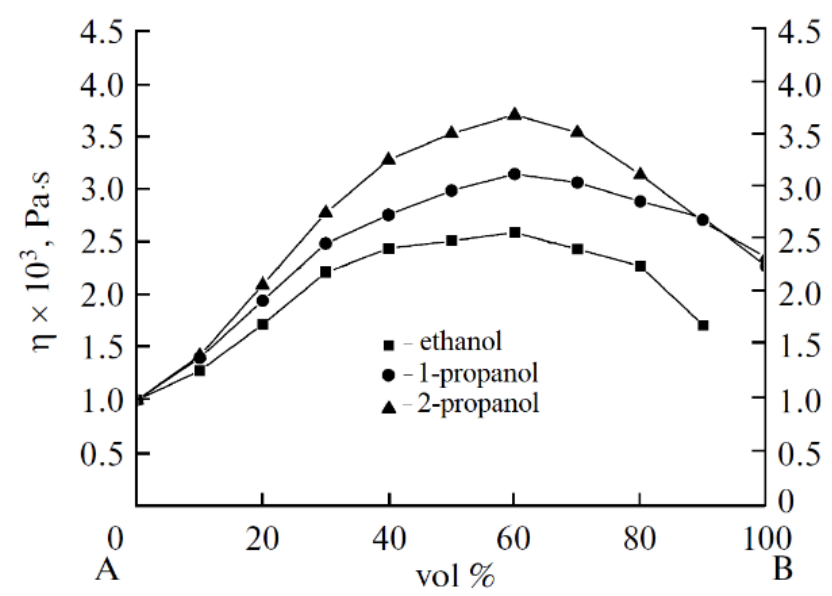

Fig. 2. The dependence of the dynamic viscosity of systems: water (A) - alcohol (B) on the volume fraction of alcohols. Based of [3].

Alcohols have very good wetting properties, thanks to which they easily penetrate porous structures. The wetting tension does not change during the flow through the layer, so that the saturation rate of the layers is approximately constant. The situation is different when the hydrophobic layers are saturated with surfactant solutions. Due to the adsorption of surfactants on the solid surface the contact angle and surface tension increase. The wetting tension varies over time. The increase in surface tension is a favorable phenomenon, because the rate of capillary saturation is directly proportional to the surface tension (1). The increase the contact angle causes decrease the saturation rate until the angle reaches $90^{\circ}(\cos \theta=0)$. The liquid is not drawn into the capillary spaces. A new equilibrium condition is established in which further migration of the solution depends on the diffusion of surfactants from the space of the saturated layer to the meniscus. For very small dimensions of the capillaries, the diffusion is so slow the wetting process is almost nonexistent. Hence the conclusion that the control of wetting of fine-porous hydrophobic layers with aqueous surfactant solutions is impossible [7-10]. Comparison of the saturation kinetics of the hydrophobic peat layers with solutions of sodium dodecyl sulphate (SDS) and ethanol is shown in Fig. 3. The peat layers were $1.8 \mathrm{~cm}$ high and $2 \mathrm{~cm}^{3}$ in volume. The peat mass in the layer was $1 \mathrm{~g}$, its specific surface area $1.1 \mathrm{~m}^{2} / \mathrm{g}$.

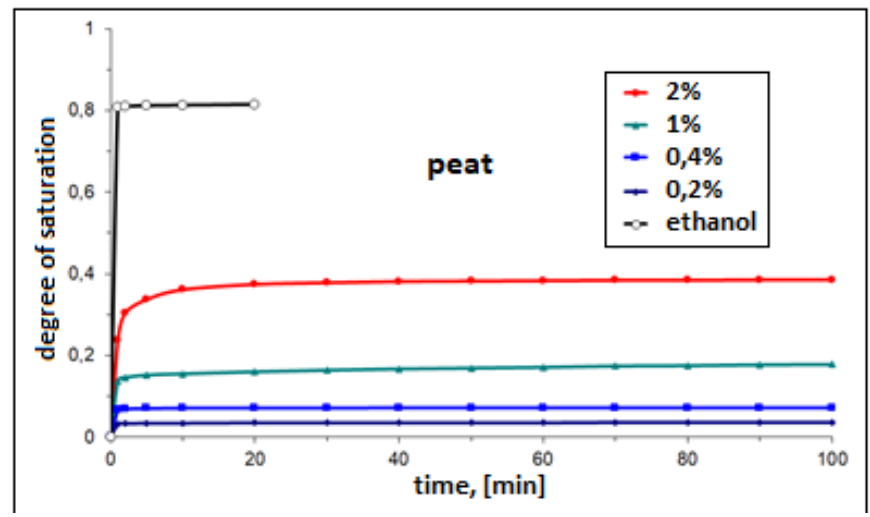

Fig. 3. Saturation of peat layers with ethanol and aqueous SDS solutions. Based on [9]. 
The stopping of the saturation of the layers with SDS solutions takes up to one minute, after which the saturation rate in the second stage is close to zero and independent of SDS concentration. Pure ethanol saturates the layer in less than a minute.

Short-chain alcohols adsorb well from aqueous solutions on solid materials. In research[11] the adsorption of ethanol and 1-propanol on non-porous coals was investigated. Fig. 4 shows the adsorption isotherms on granulated carbon Spheron- 6 with a specific surface area of $114 \mathrm{~m}^{2} / \mathrm{g}$. The specific surface area was determined by the lowtemperature nitrogen adsorption (BET) method. The maximum ethanol adsorption is 0.4 $\mathrm{mmol} / \mathrm{g}$ at a solution concentration of $3.4 \mathrm{~mol} / \mathrm{dm}^{3}$ (about $10 \% \mathrm{wt}$.), and 1 -propanol -0.5 $\mathrm{mmol} / \mathrm{g}$ at a concentration of $2 \mathrm{~mol} / \mathrm{dm}^{3}$ (about 16\%) wt.). Over 3 times less values equilibrium adsorption of SDS on hydrophobic peat were obtained in studies $[8,10]$.

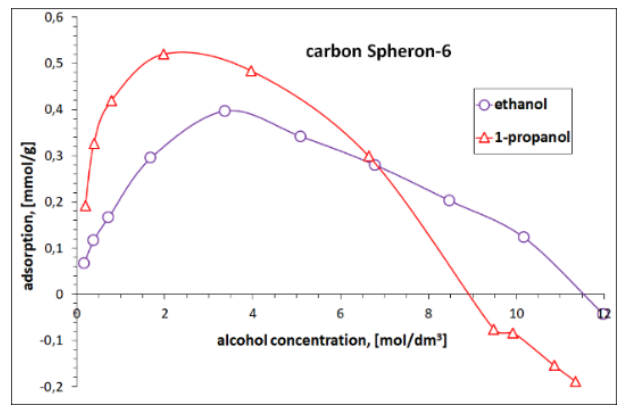

Fig. 4. Adsorption isotherms of ethanol and 1-propanol on carbon Spheron-6. Based on [11].

Higher values of alcohols adsorption are obtained on microporous materials. Adsorption of ethanol and 1-propanol on zeolites from $2 \%$ vol. solutions have been described in [12]. Selected results are presented in tab. 1.

Table. 1. Adsorption of alcohols from $2 \%$ aqueous solutions on zeolites (100 mg zeolite $/ 10 \mathrm{~cm}^{3}$ solution). Based on [12].

\begin{tabular}{|l|l|c|c|}
\hline \multirow{2}{*}{ zeolite } & \multirow{2}{*}{ alcohol } & \multicolumn{2}{|c|}{ adsorption } \\
\cline { 3 - 4 } & & {$[\mathbf{m g} / \mathbf{g}]$} & [mmol/g] \\
\hline \multirow{3}{*}{ Silicalite-1 } & $1-\mathrm{C}_{3} \mathrm{H}_{7} \mathrm{OH}$ & 105 & 1,75 \\
\cline { 2 - 4 } & $\mathrm{C}_{2} \mathrm{H}_{5} \mathrm{OH}$ & 82 & 1,78 \\
\hline \multirow{3}{*}{ F-Silicalite } & $1-\mathrm{C}_{3} \mathrm{H}_{7} \mathrm{OH}$ & 82 & 1,37 \\
\cline { 2 - 4 } & $\mathrm{C}_{2} \mathrm{H}_{5} \mathrm{OH}$ & 70 & 1,52 \\
\hline \multirow{2}{*}{ Silicalite-2 } & $1-\mathrm{C}_{3} \mathrm{H}_{7} \mathrm{OH}$ & 65 & 1,08 \\
\cline { 2 - 4 } & $\mathrm{C}_{2} \mathrm{H}_{5} \mathrm{OH}$ & 45 & 0,98 \\
\hline \multirow{2}{*}{ Alpo-5 } & $1-\mathrm{C}_{3} \mathrm{H}_{7} \mathrm{OH}$ & 23 & 0,38 \\
\cline { 2 - 4 } & $\mathrm{C}_{2} \mathrm{H}_{5} \mathrm{OH}$ & 18 & 0,39 \\
\hline
\end{tabular}

Similarly, high adsorption values are obtained for anionic surfactants (SDS) on activated carbons $[8,10]$. Therefore, it is expected that the flow of dilute solutions of 
aqueous alcohols by hydrophobic porous beds will be similar to aqueous solutions of surfactants - in two stages, with the change of the saturation rate, as shown in figure 3 [9].

\section{Materials and test methods}

In the presented studies three alcohols: ethanol 99.8\%, 1-propanol 99.5\% and 2-propanol > $99 \%$ were used.

Wetting abilities of aqueous solutions of alcohols were tested by two methods:

- measuring the wetting hysteresis of hydrophobic smooth surfaces

- kinetics of imbibition of hydrophobic layers.

The wetting hysteresis of Teflon and polyethylene was tested by Wilhelmy's method, using Krüss K-100 MK-2 tensiometer. The solutions were prepared using demineralized water at a temperature of $20 \pm 1^{\circ} \mathrm{C}$. Each measurement was repeated a minimum of three times, taking as a result the arithmetic mean. After each measurement, the plates were rinsed with demineralized water, rinsed with pure acetone and dried. The result of one single measurement were the values of advancing $(\theta n)$ and receding $(\theta \mathrm{s})$ contact angle. The difference between these values is called wetting hysteresis.

The saturation kinetics of the peat layers were tested at the experimental setup shown schematically in Fig. 5. The glass measuring cylinder had a height of $40 \mathrm{~mm}$ and an internal diameter of $14 \mathrm{~mm}$; thickness of ceramic sinter $-3 \mathrm{~mm}$. Dried, ground peat, screened on the $0.5 \mathrm{~mm}$ sieve, was tested. The layers were prepared with $0.500 \mathrm{~g}$ of peat and brought to a height of $14 \mathrm{~mm}$ by 30 seconds shaking. The layer volume was $2.2 \mathrm{~cm}^{3}$. The specific gravity of the peat $-1.41 \mathrm{~g} / \mathrm{cm}^{3}$ was determined by pycnometric method, using $99.9 \%$ ethanol and heptane as pycnometric liquid. The porosity of the layers was 0.84 .

The measuring vessel with the peat layer were put in contact with the liquid in such way that the vessel was immersed in the liquid up to the level of the upper edge of the ceramic sinter and the mass measurement was started. The program recorded the loss of mass of liquid on the scales, which corresponded to the mass of liquid absorbed by the layer.

The peat layers were saturated with water, alcohols and aqueous solutions of alcohols at $10,20,40,60$ and $80 \%$ vol. For comparison, the $1 \%$ aqueous solution of the extinguishing wetting agent was also tested. Demineralized water at $20 \pm 1^{\circ} \mathrm{C}$ was used. The ambient temperature during the measurements was $21 \pm 2{ }^{\circ} \mathrm{C}$.

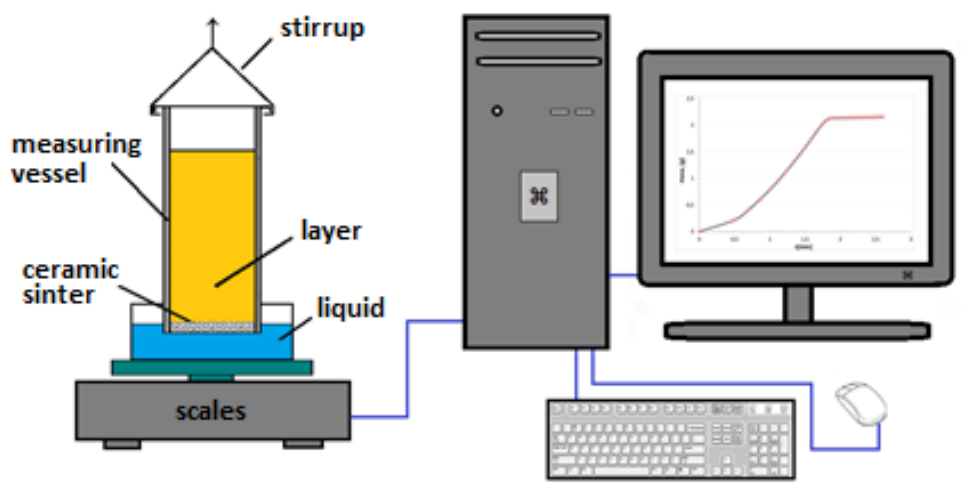

Fig. 5. Experimental setup for testing the kinetics of imbibition of peat layers.

To test the reproducibility of the results, 10 identical measurements of saturation of the peat layer were carried out with a $60 \%$ ethanol solution. The maximum deviation of weight of the absorbed solution from the average value was about $10 \%$. 


\section{Results}

Of the two investigated non-porous hydrophobic materials, Teflon was harder to wetting with alcohol solutions. In this case, excellent wetting $\left(\theta n=0^{\circ}\right)$ was not achieved for any of the alcohols. The isotherms for wetting surface of polyethylene and Teflon are shown in Fig. 6.
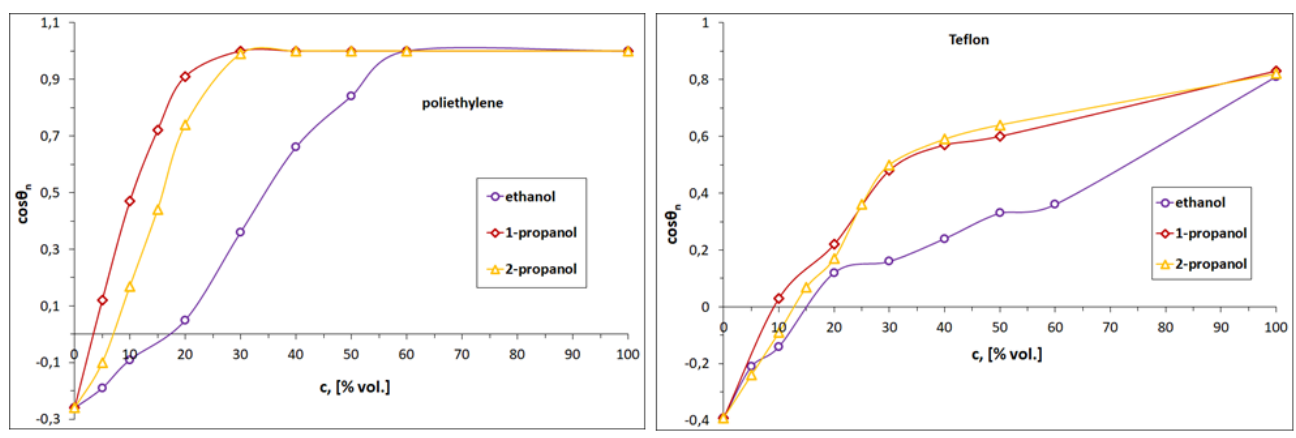

Fig. 6. Wetting isotherms of polyethylene and Teflon with alcohol solutions $\left(\theta_{n}-\right.$ advancing contact angle).

Typical for wetting isotherms of hydrophobic materials with aqueous solutions are socalled inversion points, i.e. concentrations at which the cosine of contact angle reaches zero. Above this concentration it is possible to saturate the hydrophobic material with capillary forces. The inversion points of polyethylene wetting are: ethanol - 17\%, 1propanol - 3\% and 2-propanol - 7\%, and for Teflon: ethanol - 15\%, 1-propanol - 9\% and 2propanol - $13 \%$.

The capillary saturation capacity depends not only on the cosine of the contact angle, but is also directly proportional to the surface tension of liquid. Hence, it is generally accepted as a wettability rate of porous materials, the wetting tension, which is the product of the surface tension and cosine of contact angle. Thus, the wetting isotherms can be represented as: $\sigma \cdot \cos \theta n=f(c)$ (Fig. 7).
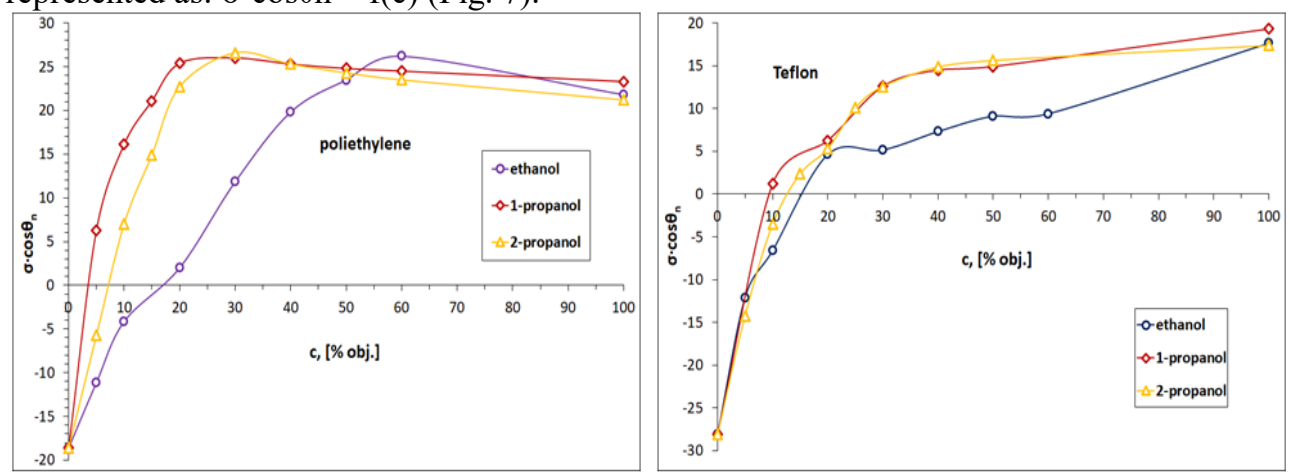

Fig. 7. Wetting tension of polyethylene and Teflon as a function of concentration of alcohol aqueous solution.

While the wetting tension of Teflon with alcohols solutions increases with the rise of concentration, in case of polyethylene it is reduced from $20 \%$ for 1 -propanol, $30 \%$ for 2 propanol and $60 \%$ for ethanol. The reduction of the wetting tension results from the fact that already from a concentration of $30 \%$ for propanols and $60 \%$ for ethanol the contact angle reaches a constant value zero $(\cos \theta=1)$, while the surface tension decreases with 
increasing alcohol concentration. The wetting tension of pure alcohols have similar values: $15-20 \mathrm{mN} / \mathrm{m}$ for Teflon and $20-25 \mathrm{mN} / \mathrm{m}$ for polyethylene.

On the basis of the wetting isotherms, you can rank the wetting abilities of the alcohols in order from the best: 1-propanol, 2-propanol, ethanol. In the case of ethanol, the receding contact angles are smaller than the advancing contact angles by approximately a constant value in the whole concentration range. The zero value of the receding contact angle is shown only by ethanol (100\%) (Fig. 8).

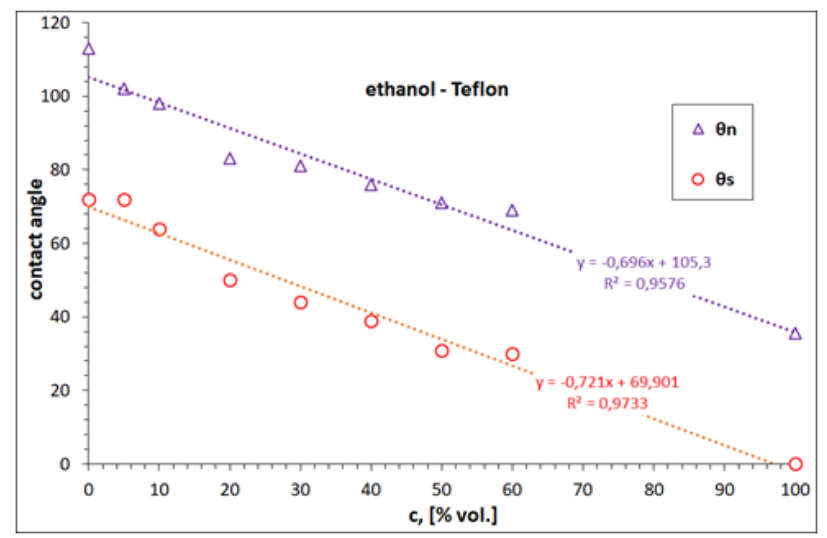

Fig. 8. Wetting hysteresis of Teflon with ethanol solutions.

The results of studies on the rate of saturation of peat layers with alcohol solutions are presented in the graphic dependence the mass of the absorbed liquid on the square root of the saturation time (Fig. 9). For comparison, the saturation of the $1 \%$ solution of fire extinguishing wetting agent was presented. This is the highest concentration of the solution of wetting agents used in extinguishing operations. In this case, complete saturation of the layer was not obtained. 

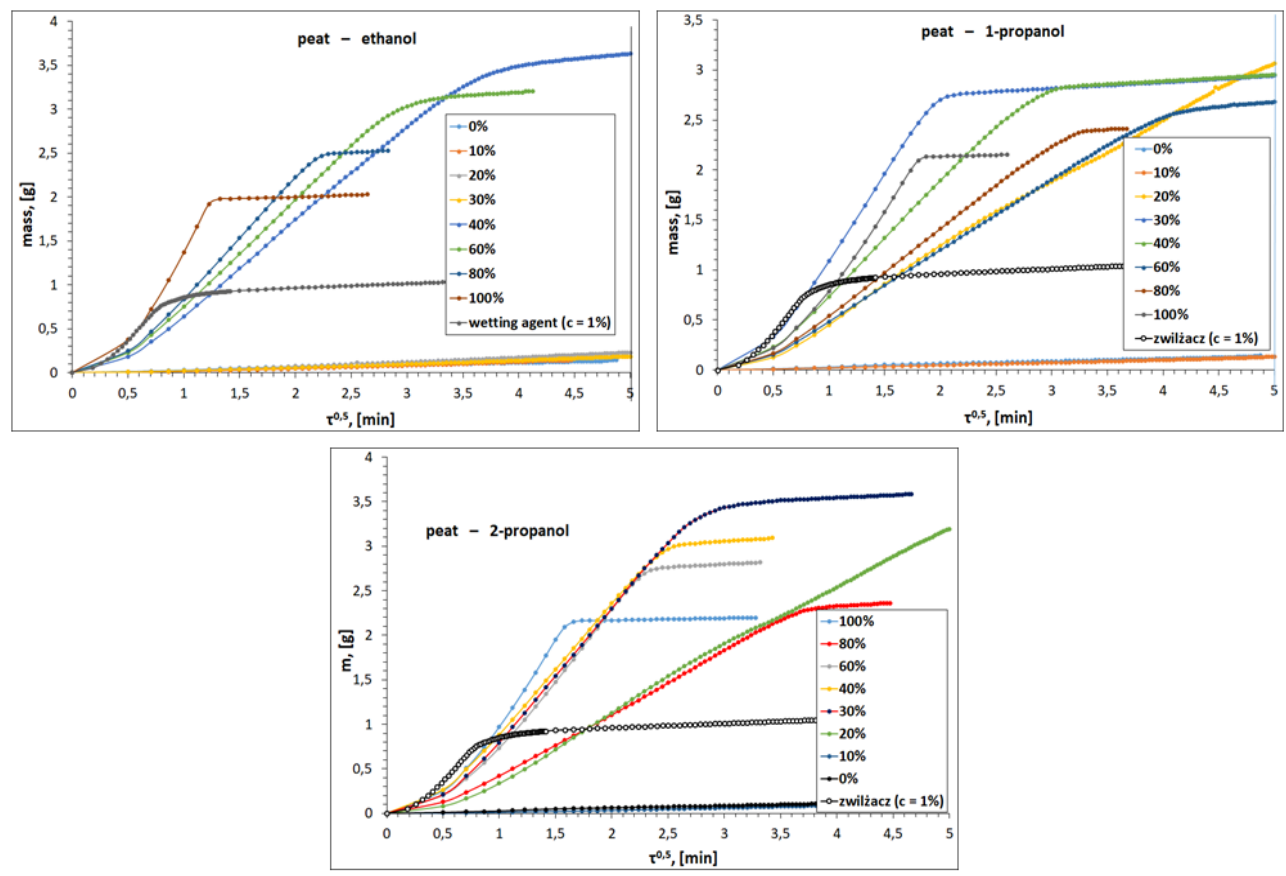

Fig. 9. The diagrams of saturation of peat layers with aqueous solutions of alcohols.

In Fig. 9, the saturation curve of the wetting agent solution has a characteristic, twostage course, typical for the imbibition of hydrophobic layers with aqueous solutions of surfactants (Fig. 4). After imbibing about $0.9 \mathrm{~g}$ of the solution, the saturation is inhibited. The volume of the porous space in the studied layers was about $1.5 \mathrm{~cm}^{3}$, so the theoretical increase in the mass of the layer during the measurement should be about up to $1.5 \mathrm{~g}$.

In the case of alcohol solutions, practically no imbibition was observed for solutions with concentrations up to $20 \%$. This corresponds to the results of the wetting properties of the hydrophobic smooth surfaces (Fig. 6 and 7). The inversion points of wetting of the tested hydrophobic materials were below $20 \%$. Solutions with concentrations greater than $20 \%$ were absorbed by the layers until full saturation, without changing the saturation rate. It's characteristic that the maximum saturation of the layers was higher than the theoretical value. The value of maximum saturation decreased with the increase of alcohol concentration. It means that during impregnation, the layers increase their volume, and this increase depends on the water content in the solution, provided that the solution wets the material (peat) well $\left(\theta<90^{\circ}\right)$. The saturation rate of the layers increases with rising alcohol concentration and is the highest for pure alcohols. The shortest saturation time with pure alcohols was obtained for ethanol, which is probably related to its clearly lower viscosity in comparison to propanols. (Fig. 2).

\section{Conclusions}

- The wetting properties of the tested alcohols in relation to the hydrophobic smooth surfaces can be arranged as follows: 1-propanol> 2-propanol> ethanol.

- The ability of alcohols to saturate peat layers can be ranked using the saturation time criterion as follows: ethanol, 2-propanol, 1-propanol. 
- The alcohol solutions wets the peat layers at concentrations above $20 \%$ with a constant saturation rate, which increases with rising alcohol concentration.

- During the saturation with aqueous solutions of alcohols, the volume of the layers increases.

\section{References}

1. G. Vazquez, E. Alvarez, J.M. Navaza, J. Chem. Eng. Data 40/3, 611 (1995)

2. H. Ghahremani, A. Moradi, J. Abedini-Torghabeh, S.M. Hassani, Der Chemica Sinica, 2/6, 212 (2011)

3. V.I. Kuchuk, I.Yu. Shirokova, E.V. Golikova, Glass Phys. Chem. 38/5, 460 (2012)

4. M. Ageno, C. Frontali, Proc. Natl. Acad. Sci. U.S.A. 57, 856 (1967)

5. B. Jańczuk, T. Białopiotrowicz, W. Wójcik, Colloids Surf. A 36, 391 (1989)

6. P. Basařová, T. Váchová, L. Bartovská, Colloids Surf. A 489, 200 (2016)

7. G.A. Aksielrud, M.A. Altszuler, Ruch masy w ciałach porowatych (WNT, Warszawa, 1987)

8. S. Neffe, A. Mizerski, Przem. Chem. 11, (2000)

9. S. Neffe, A. Mizerski, Przem. Chem. 2, (2001)

10. A. Mizerski, S. Neffe, Biuletyn Wojskowej Akademii Technicznej 61/1, 395 (2012)

11. R.P. Craig, R.S. Hansen, Ames Laboratory ISC Technical Reports, 3, (1953)

12. B. Cekova, D. Kocev, E. Kolcakovska, D. Stojanova, Acta Period. Techn. 37, 83 (2006) 